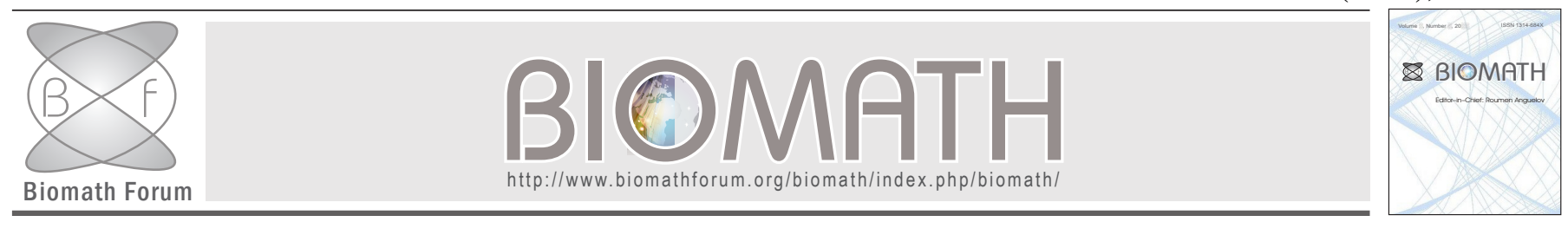

\title{
From the Guest-Editor
}

The BIOMATH 2012 International Conference on Mathematical Methods and Models in Biosciences was held at the Bulgarian Academy of Sciences in Sofia, in June 17-22, 2012, http://www.biomath.bg/2012/. We were happy to meet more than 70 participants from twenty different countries. More than 40 contributions were submitted for publication in the present BIOMATH proceedings. All submitted papers have been peer-reviewed by at least two independent anonymous reviewers. Twelve selected papers are published in the first issue of this journal. This second issue contains another ten selected contributions which will be published continuously in the electronic version of the journal. We are grateful for the support provided by several academic units and universities and to all members of the Program and Organizing Committees for their active help in the organization of the BIOMATH 2012 International Conference. We thank also all participants for their contribution to the success of this Conference. We are especially grateful to all reviewers for their time and efforts.

With deep sorrow we announce at the end of the issue the sudden deaths of two dear colleagues of us who were very helpful in the organization of the BIOMATH conferences: Stefan Dodunekov and Anthony Popov. Academician Stefan Dodunekov, President of the Bulgarian Academy of Sciences, was Chairman of the BIOMATH 2011 and BIOMATH 2012 conferences. Dr. Anthony Popov, from the Faculty of Mathematics and Informatics at the University of Sofia "Kl. Ohridski", was the main organizer of the School for Young Scientists at the BIOMATH 2011 and BIOMATH 2012 conferences.

Svetoslav Markov

http://dx.doi.org/10.11145/j.biomath.2012.11.113 